\title{
Forest Leaf Area Index Inversion Based on Landsat OLI Data in the Shangri-La City
}

\author{
Yuanhe $\mathrm{Yu}^{1,2,3} \cdot$ Jinliang Wang ${ }^{1,2,3} \cdot$ Guangjie Liu ${ }^{1,2,3} \cdot$ Feng Cheng ${ }^{1,2,3}$
}

Received: 6 July 2018 / Accepted: 16 January 2019/Published online: 8 February 2019

(C) The Author(s) 2019

\begin{abstract}
Leaf Area Index (LAI) is an important index that reflects the growth status of forest vegetation and land surface processes. It is of important practical significance to quantitatively and accurately estimate Leaf Area Index. We used the Landsat-8 operational land imager single-band images, and 15 vegetation indices that were extracted from the multi-band were combined with the LAI data measured from the CI-110 canopy digital imager to establish the LAI estimation model. Through the leave-one-out cross-validation method, the accuracy of various model estimation results was verified and compared, and the optimal estimation model was obtained to generate the LAI distribution map of Shangri-La City. The results show that: (1) the multivariable model method is better than the single-variable model method when estimating LAI, and its determination coefficient is the highest $\left(R^{2}=0.7903\right)$. (2) The full-sample dataset is divided into Alpine Pine forest, Oak forest, Spruce-fir forest, and Yunnan Pine forest for analysis. The coefficient of determination of the model simulation is improved to varying degrees, and the highest $R^{2}$ increased by $0.1652,0.1040,0.1264$, and 0.0079 , respectively, over the full-sample. The corresponding best models are LAI-DVI (Difference Vegetation Index), LAI-NNIR (normalized near-infrared), LAI-NMDI (Normalized Multi-band Drought Index), and LAI-RVI (Ratio Vegetation Index). (3) The LAI values in Shangri-La City ranged from 0.9654 to 5.5145 and are mainly concentrated in high vegetation coverage areas; and the higher the vegetation coverage level, the higher the LAI value.
\end{abstract}

Keywords Leaf Area Index $\cdot$ Vegetation index $\cdot$ Landsat OLI $\cdot$ Shangri-La City $\cdot$ Forest

Jinliang Wang

wang_jinliang@hotmail.com

Yuanhe Yu

14787870652@163.com

Guangjie Liu

guangjiers@gmail.com

Feng Cheng

chengfeng_rs@163.com

1 College of Tourism and Geographic Sciences, Yunnan Normal University, Kunming 650500, Yunnan, China

2 Key Laboratory of Resources and Environmental Remote Sensing for Universities in Yunnan, Kunming 650500, Yunnan, China

3 Center for Geospatial Information Engineering and Technology of Yunnan Province, Kunming 650500, Yunnan, China

\section{Introduction}

Leaf Area Index (LAI) is defined as one-half of the total green leaf area (all sides) per unit of ground surface area (Chen and Black 2010). Among many surface biogeochemical parameters that can be derived from satellite spectral measurements, LAI is a vegetation structural parameter of fundamental importance for the quantitative analysis of many physical and biological processes related to vegetation dynamics and their effects on the global carbon cycle and climate (Chen et al. 2002). LAI is an important input factor for the study of the forest carbon cycle and water cycle mechanism models (Chang et al. 2016), which are vital to describe the vegetation canopy and assess plant growth conditions and their health status (Wang et al. 2018). LAI also plays an important role in the quantitative remote sensing inversion of vegetation and is widely used in the research of vegetation canopy reflectance models and climate models (Ren et al. 2015). 
Forest land LAI measurement methods include direct and indirect measurements. Although the direct measurement of the LAI method has high precision, it is very laborious and destructive to the plant itself (Zhu et al. 2014). It is also time-consuming, labor-intensive or simply unattainable, as well as difficult to expand to a large area LAI measurement (Han et al. 2014). Therefore, LAI observation mostly uses indirect measurement methods. The indirect measurement method uses some measurement parameters or optical instruments to obtain the Leaf Area Index, which is convenient and quick to measure. These include the TRAC plant canopy analyzer, the AccuPAR plant canopy analyzer, the LAI-2000 plant canopy analyzer, and the CI-110 vegetation canopy digital imager. However, the results obtained by indirect methods need to be corrected. With increasing interest in LAI spatial models and the need for scientific research, the use of remote sensing data to estimate LAI has become the most attractive method because it provides the most effective method for large area LAI estimation ( $\mathrm{Li}$ et al. 2014; He et al. 2013; Zhang et al. 2018). The quantitative inversion of LAI based on remote sensing methods usually includes an optical model method and a statistical model method. The former has a certain universality, but the inversion is time-consuming and the operation is complex, which can result in an incorrect inversion result (Wang et al. 2015; Li et al. 2011). The statistical model method aims to establish a linear or nonlinear model between the measured LAI and the vegetation index to achieve an estimation of the LAI (Han et al. 2014). The model is simple and easy to calculate and has high precision, but it requires a large amount of measured data (Wang et al. 2016).

Many scholars have conducted LAI studies based on a statistical model of vegetation index. These researchers methods include using TM data as the data source to analyze the correlation between vegetation index and measured LAI (Xu et al. 2003), using the best vegetation index model to construct the LAI estimation model of forest land using random forest (Yao et al. 2017), and using the method of inverting the corn canopy Leaf Area Index by using the vegetation index as a preliminary judgment basis for the growth status of maize ( $\mathrm{Su}$ et al. 2018). The radiation transmission model was used to estimate the forest LAI model, and the NDVI-LAI (Normalized Difference Vegetation Index and Leaf Area Index) relationship of deciduous forest land was studied during 1996-2001 (Wang et al. 2005). These studies were focused on the assessment of a LAI model inversion approach applied to multitemporal optical data over an agricultural region that had various crop types with different crop calendars (González-Sanpedro et al. 2008). The relationship between LAI and NDVI was quantified using empirical relationships between plant community-specific LAI and daily scale accumulation (with a $0{ }^{\circ} \mathrm{C}$ threshold) (Juutinen et al. 2017).

The above research shows that using the empirical relationship between vegetation index and measured LAI, the LAI inversion model provides an effective technical means for LAI estimation research in areas with complex terrain and difficult conditions, such as hard to reach artificial measurement areas. However, the research divides the samples into modeling sets and inspection sets and adopts a sample retention test method, which greatly reduces the sample utilization rate. This makes it more difficult to perform work for Leaf Area Index acquisition in large regions and in difficult environments. The leave-oneout cross-validation (LOOCV) method can be used for the study of fewer sample points.

In this study, therefore, our objective is to use the single-band data of remote sensing data and multiple vegetation indices calculated through multiple bands to conduct regression analysis with the land surface measured forestland LAI data. Using this method, an optimal estimation model for LAI remote sensing inversion of forest land (including forest types) is established. The accuracy of the remote sensing inversion model is verified by the LOOCV method. This provides a reference for the inversion of LAI in the woodland of Shangri-La City using empirical statistical models. Landsat OLI was used as the data source for remotely sensed data, and the LAI data were measured using the CI-110 vegetation canopy digital imager as a field acquisition tool to collect the LAI of each forest land from July-September 2016 and JulySeptember 2017.

\section{Data and Methods}

\section{Study Area}

Shangri-La City, located in the northwestern part of the Yunnan Province, China, is situated in the Hengduanshan area in the eastern part of the Three Parallel Rivers, and its geographical position is $26^{\circ} 52^{\prime}-28^{\circ} 52^{\prime} \mathrm{N}, 99^{\circ} 20^{\prime}-$ $100^{\circ} 19^{\prime} \mathrm{E}$. The total area of the city is $11,600 \mathrm{~km}^{2}$ (Fig. 1). Most areas of Shangri-La City are subalpine, alpine landform with elevations above $3000 \mathrm{~m}$; the vegetation type is cold-temperate and cool-temperate coniferous forest. There are 43 species of major forest trees, including 10 species of coniferous forests, 33 species of broadleaf forests, and a wide distribution of Abies, Picea, Sequoia, Alpine Pine, Yunnan pine, Quercus Aquifolioides, Red Birch, White Birch, etc. The city's forest land area is $962,159.3$ hectares, with the total volume of $133,224,410$ cubic meters. The forest coverage rate is 


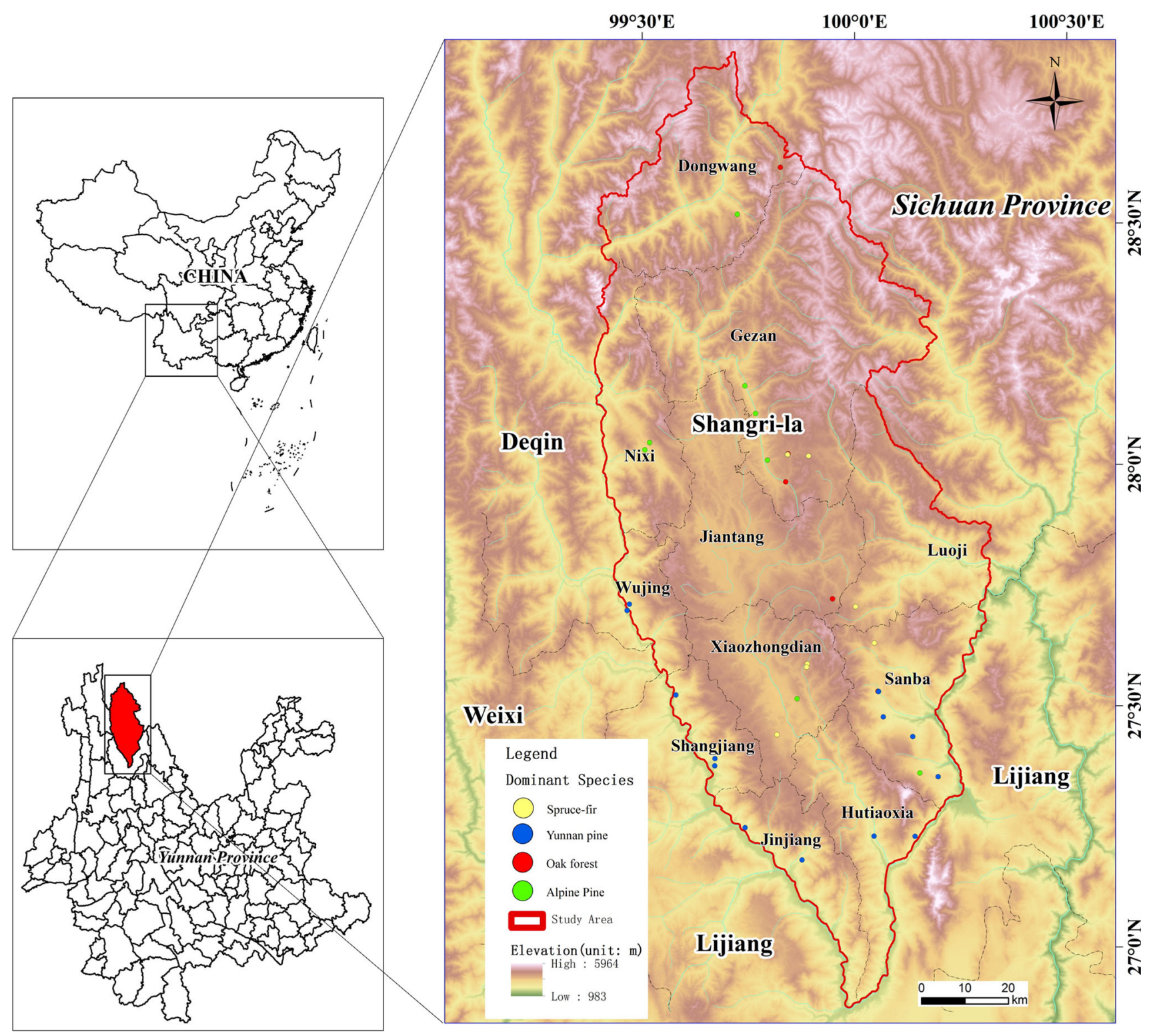

Fig. 1 Location of Shangri-La City, Yunnan Province, China

$76.00 \%$, the green area of the forest is $83.19 \%$, and the public welfare forest and analyzing ratio is 89.47:10.53. The forest is mainly divided into Bract Fir forest, Cangshan Fir forest, Lijiang Spruce forest, Alpine Pine forest, Quercus Aquifolioides and Yunnan Pine forest, Larch (Large Sequoia), Yunnan Hemlock forests, Populus szechuanica Schneid, White Birch forests and Acer, Birch forest, etc. The Oak forest, Yunnan Pine forest, Alpine Pine forest, and Spruce-fir forest (including Abies Georgei forest, Cangshan Fir forest, and Lijiang Spruce forest) account for $90.8 \%$ of ash forests in Shangri-La City; therefore, LAI inversion studies are primarily performed on these 4 kinds of forest species.

\section{Data Sources}

\section{Landsat 8 OLI Image}

Shangri-La City has distinct wet and dry seasons; the summer and autumn seasons (June to October each year) are dominated by rainy days; therefore, remote sensing images have a greater cloud cover. Thus, the dry season remote sensing image (December 2016 Landsat OLI image) was selected as the data source, and the data acquisition dates were December 6, 2016 (strip number 131, line number 41) and December 13, 2016 (strip number 132, line numbers 40-41), when the cloud volume was below $1.18 \%$. These data include 7 multispectral bands 
Table 1 Results of LAI for descriptive statistics

\begin{tabular}{lclllllr}
\hline Types & Sample numbers & Minimum & Maximum & Average & SD & Skewness & Kurtosis \\
\hline Alpine Pine & 9 & 1.01 & 3.21 & 1.73 & 0.64 & 1.14 & 1.07 \\
Oak & 5 & 1.40 & 2.35 & 1.81 & 0.34 & 0.46 & -0.85 \\
Spruce-fir & 7 & 0.56 & 2.14 & 1.51 & 0.52 & -0.61 & -0.21 \\
Yunnan Pine & 13 & 1.05 & 2.96 & 1.76 & 0.46 & 1.13 & 2.44 \\
Full-sample & 34 & 0.56 & 3.21 & 1.73 & 0.53 & 0.65 & 1.30 \\
\hline
\end{tabular}

with $30 \mathrm{~m}$ resolution (wavelength range of $0.43-2.29 \mu \mathrm{m}$ ), one panchromatic band with $15 \mathrm{~m}$ resolution (wavelength range of $0.50-0.68 \mu \mathrm{m}$ ), and 2 thermal infrared bands with $100 \mathrm{~m}$ resolution (wavelength range of 10.6-12.5 $\mu \mathrm{m}$ ). The images were downloaded from the USGS (https://glovis. usgs.gov/).

\section{LAI Measured Data}

The common types of forests in Shangri-La City are mainly Alpine Pine forests, Oak forests, Spruce-fir forests, and Yunnan Pine forests; therefore, LAI data of these 4 common species were obtained. The collections were conducted in 3 time periods from August 27 to September 2, 2016, July 17 to July 26 and September 24 to September 30, 2017. First, using the CI-110 vegetation canopy digital imager produced by CID, USA, indirect measurements of plant canopy-related parameters were taken, and parameters such as Leaf Area Index, average blade inclination angle, and scattered radiation transmittance were calculated. The instrument was purchased from Zealquest Scientific Technology Co., Ltd., located at 8th Floor, Building 2, East China Normal University Science and Technology Park, 1038 Jinshajiang Road, Shanghai (Postal Code: 200062). The most suitable sky condition for measurements is clear morning or evenings, that is, when the amount of scattered radiation is low. When measured under clear-sky conditions, the fisheye lens of the CI-110 vegetation canopy digital imager should be placed in the shade or shadow to reduce the underestimation of LAI and the overestimation of direct and diffuse radiation transmission coefficients. The distance of the nearest leaf in the direction of the fisheye lens to a 30-degree zenith angle should be at least 4 times the width of the blade. Several more measurements to reduce the size of the image were taken, and so the average number of images depends on the canopy structure and its distribution. Therefore, 40 sample plots were randomly selected in Shangri-La City for LAI measurements, with a size of $30 \mathrm{~m} \times 30 \mathrm{~m}$ (corresponding to the spatial resolution of $30 \mathrm{~m}$ of the OLI image). A plurality of LAI values is measured in 4 different directions in a range of $30 \mathrm{~m} \times 30 \mathrm{~m}$ around the center point in a total of 4 different directions is calculated to be the LAI value of the sample; and the center point latitude and longitude are recorded by a handheld GPS. By eliminating 6 sets of obvious error plots, the available data consisted of 34 groups, including 7 groups of Spruce-fir forests, 9 groups of Alpine Pine forests, 5 groups of Oak forests, and 13 groups of Yunnan Pine forests. The description statistics of the LAI sampling data are shown in Table 1.

\section{Auxiliary Data}

Auxiliary data include Shangri-La City vector zoning data and land use classification maps. The land use data are from the Chinese land use data for 2015 from the Chinese Academy of Sciences' Resource and Environment Science Data Center. The data update is based on the 2010 data that is based on Landsat 8 remote sensing images and is generated through manual interpretation. The land use types include 6 first-level types and 25 second-level types of cultivated land, forest land, grassland, water areas, residential areas, and unused land. China's land use remote sensing monitoring database is China's highest accuracy database of land use remote sensing monitoring data products, which has played an important role in the national land resources survey, hydrology, and ecological research. Therefore, the land use pattern is used to further analyze the spatial distribution of LAI.

\section{Methods}

Based on the Landsat OLI data calculated radiation, atmospheric correction, and other preprocessing, the multiband vegetation index was calculated. The field data obtained were used for the elimination of invalid data and the classification of sample types. The 34 measured samples were separated from the single-band and multi-band regression analysis that was performed to establish the LAI model. Using the LOOCV method to evaluate the accuracy of the model, the best sample models for the full-sample and each sample were selected. Finally, the LAI was inverted, and the LAI status of the Shangri-La City forest land was analyzed in combination with land use types and vegetation coverage. 


\section{Univariate Model Method}

Seven bands of Landsat OLI multispectral data were used to perform the quadratic polynomial regression analysis with the measured LAI, and a regression model for the single-band gray value and LAI was established.

\section{Multivariate Modeling Method}

Vegetation index is a unique numerical value that indicates the reflectivity of ground objects in 2 or more wavelength ranges by using linear or nonlinear calculations to generate certain indications of vegetation growth and biomass (Luo et al. 2012). Fifteen broadband vegetation indices that are sensitive to LAI to be used to estimate LAI were selected. Statistical regression was performed between each vegetation index and measured LAI, and a fitting model in the form of a linear function was established. The formulas for calculating the vegetation indices are shown in Table 2.

\section{Estimation of Vegetation Coverage}

A dimidiate pixel model is a kind of vegetation coverage estimation model that is simple and practical. It considers remote sensing sensor information $S$, the green vegetation information contribution of $S_{\mathrm{v}}$, and the covered with no vegetation (bare soil) contribution of $S_{\mathrm{S}}$ (Li et al. 2004). The dimidiate pixel model of vegetation coverage is:
$\mathrm{FVC}=\left(S-S_{\mathrm{S}}\right) /\left(S_{\mathrm{v}}-S_{\mathrm{S}}\right)$,

In the formula, FVC represents the vegetation coverage, $S$ represents the vegetation index of the pixel, $S_{\mathrm{v}}$ is the vegetation index information of the surface completely covered by vegetation, and $S_{\mathrm{S}}$ is the vegetation index information of the bare soil surface. In the following formula, $N D V I$ replaces $S$, NDVI $I_{\text {min }}$ replaces $S_{\mathrm{S}}$, and $\mathrm{NDVI}_{\max }$ replaces $S_{\mathrm{v}}$ :

$\mathrm{FVC}=\left(\mathrm{NDVI}-\mathrm{NDVI}_{\min }\right) /\left(\mathrm{NDVI}_{\max }-\mathrm{NDVI}_{\min }\right)$,

In the vegetation coverage estimation model based on the dimidiate pixel, the extreme values of $N D V I$ are not necessarily $\mathrm{NDVI}_{\max }$ and $\mathrm{NDVI}_{\text {min }}$ due to the inevitable noise in the image. Therefore, in this paper, we take the maximum and minimum values within the confidence interval of 5-95\%.

\section{Results}

\section{Estimating LAI by the Univariate Model Method}

In the LAI regression analysis using the single-band of the full-sample, the determination coefficient is very low, and the highest near-infrared band is only 0.1211 , which indicates that the LAI inversion of woodland using a singlevariable model has low precision and a large inversion error (Table 3).

Table 2 Vegetation indices and expressions

\begin{tabular}{ll}
\hline Vegetation index & Expression \\
\hline Ratio Vegetation Index (Jordan 1969) & RVI $=$ nir $/ r$ \\
Normalized near-infrared (Sripada et al. 2005) & NNIR $=$ nir/(nir $+r+$ green $)$ \\
Soil Adjusted Vegetation Index (Huete 1988) & SAVI $=1.5 \times($ nir $-\mathrm{r}) /($ nir $+r+0.5)$ \\
Normalized Difference Vegetation Index & NDVI $=($ nir $-r) /($ nir $+r)$ \\
Wide Dynamic Range Vegetation Index (Huang et al. 2017) & WDRVI $=(0.2 \times$ nir $-r) /(0.2 \times$ nir $+r)$ \\
Normalized red band (Sripada et al. 2005) & NR $=r /($ nir $+r+$ green $)$ \\
Green Normalized Difference Vegetation Index (Gitelson et al. 1996) & GNDVI $=($ nir - green $) /($ nir + green $)$ \\
Difference Vegetation Index (Tucker 1979) & DVI $=$ nir $-r$ \\
Renormalized Difference Vegetation Index (Roujean and Breon 1995) & RDVI $=\sqrt{(\text { nir }-r)^{2} /(\text { nir }+r)}$ \\
Normalized Multi-band Drought Index (Wang and Qu 2007) & NMDI $=($ nir $-(\mathrm{swir} 1-$ swir2))/(nir $-($ swir1 + swir2)) \\
Structure Insensitive Pigment Index (Penuelas et al. 2010) & SIPI $=($ nir - blue $) /($ nir + blue $)$ \\
Normalized green-band (Sripada et al. 2005) & NG $=$ green/(nir $+r+$ green $)$ \\
Green Ratio Vegetation Index (Gitelson et al. 1996) & GRVI $=$ nir/green -1 \\
Modified Soil Adjusted Vegetation Index (Qi et al. 1994) & MSAVI $=2 \times$ nir $+1-\sqrt{(2 \times \text { nir }+1)^{2}-8 \times(\text { nir }-r) / 2}$ \\
Plant Senescence Reflectance Index (Merzlyak et al. 2010) & PSRI $=(r-$ blue $) /$ nir \\
\hline
\end{tabular}

blue, green, $r$, nir, swirl, and swir2, respectively, represent the reflectance of blue, green, red, near-infrared, shortwave infrared 1, and shortwave infrared 2 in Landsat 8 images, respectively 
Table 3 Quadratic polynomial regression relationship between full-sample LAI and single-band reflectivity

\begin{tabular}{|c|c|c|c|c|c|c|}
\hline Band & Blue & Green & Red & Near-infrared & Short wave infrared 1 & Short wave Infrared 2 \\
\hline$R^{2}$ & 0.0677 & 0.1114 & 0.0981 & 0.1211 & 0.0642 & 0.0961 \\
\hline
\end{tabular}

\section{Estimating LAI by the Multivariate Model Method}

A linear regression analysis was carried out with 15 planting cover indices and all of the samples: Alpine Pine forest sample, Oak forest sample, Spruce-fir sample and Yunnan Pine sample LAI (Fig. 2). The correlation is shown in Table 4. We know that: (1) whether it is a regression analysis of the all of the samples or a regression analysis of the forest land in the 4th sample, the multiple vegetation indices extracted from remote sensing images have a good correlation with the measured LAI. The highest correlation indices of full-sample, Alpine Pine, Oak, Spruce-fir, and Yunnan Pine are RVI $\left(R^{2}=0.6251\right)$, DVI $\left(R^{2}=0.7903\right)$, WDRVI $\left(R^{2}=0.7439\right)$, NMDI $\left(R^{2}=0.7515\right)$, and RVI $\left(R^{2}=0.6330\right)$, respectively. From these expressions, it is not difficult to find that the near-infrared and red band are the best expressions of LAI, with the combination of shortwave infrared and near-infrared. (2) From the regression analysis of the measured LAI and all sample
Fig. 2 The relationship between 4 well-fitting vegetation indices and measured LAI in the fullsample
Table 4 Linear regression relationship between LAI and the vegetation index of various samples
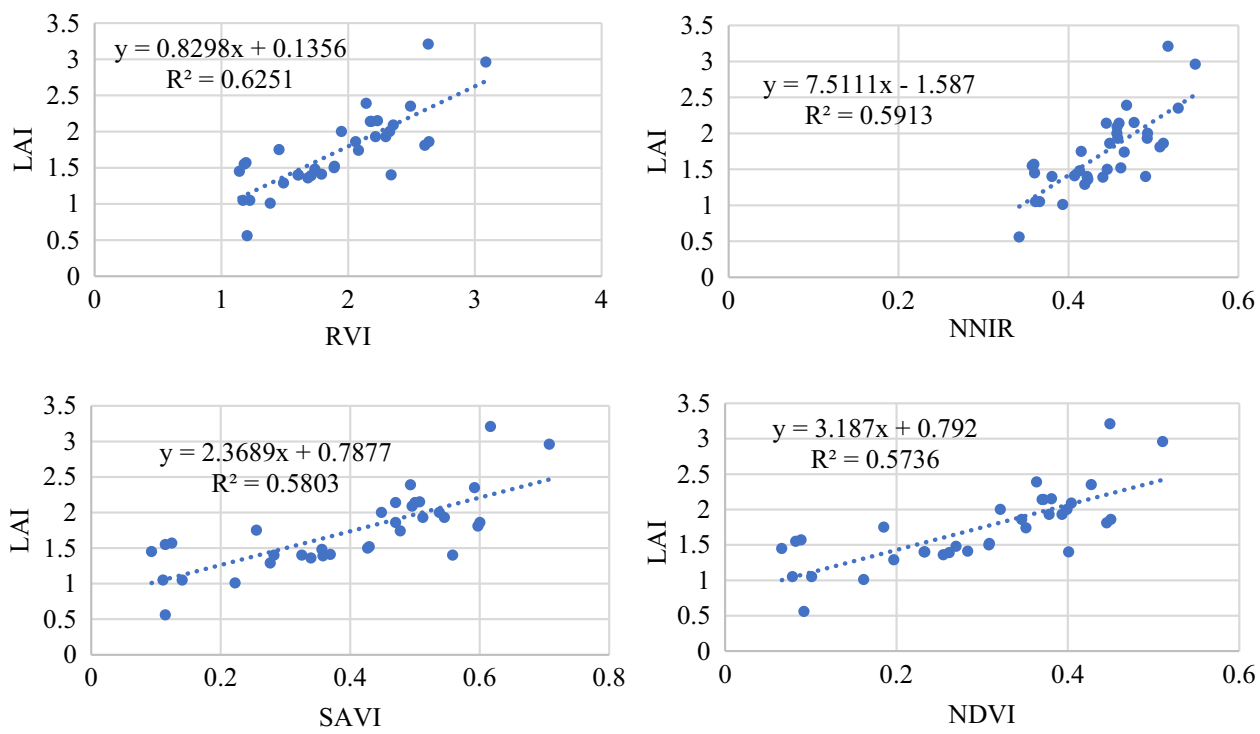

\begin{tabular}{llllll}
\hline VI & Full-sample & Alpine Pine forest & Oak forest & Spruce-fir forest & Yunnan Pine forest \\
\hline RVI & 0.6251 & 0.7033 & 0.6429 & 0.6266 & 0.633 \\
NNIR & 0.5913 & 0.7102 & 0.7291 & 0.7331 & 0.5484 \\
SAVI & 0.5803 & 0.7464 & 0.6772 & 0.6214 & 0.5296 \\
NDVI & 0.5736 & 0.7161 & 0.6586 & 0.6256 & 0.5232 \\
WDRVI & 0.5082 & 0.6406 & 0.7439 & 0.6305 & 0.4931 \\
NR & 0.5063 & 0.6828 & 0.4103 & 0.4703 & 0.502 \\
GNDVI & 0.5013 & 0.629 & 0.6876 & 0.6557 & 0.4622 \\
DVI & 0.4487 & 0.7903 & 0.5984 & 0.2397 & 0.474 \\
RDVI & 0.4148 & 0.6581 & 0.6633 & 0.2435 & 0.4173 \\
NMDI & 0.3915 & 0.4371 & 0.0092 & 0.7515 & 0.3294 \\
SIPI & 0.2745 & 0.5811 & 0.5708 & 0.072 & 0.23 \\
NG & 0.26 & 0.3669 & 0.636 & 0.0968 & 0.2408 \\
GRVI & 0.11 & 0.1064 & 0.4438 & 0.218 & 0.2824 \\
MSAVI & 0.0703 & 0.1642 & 0.3747 & 0.0003 & 0.0429 \\
PSRI & 0.0018 & 0.0043 & 0.4047 & 0.0169 & 0.0293 \\
\hline
\end{tabular}


Table 5 The correlation between the analog value of each sample model and measured values

\begin{tabular}{lcccc}
\hline Full-sample model & LAI-RVI & LAI-NDVI & LAI-SAVI & LAI-NNIR \\
\hline$R$ & 0.7501 & 0.7088 & 0.7138 & 0.7251 \\
RMSEP & 0.3436 & 0.3669 & 0.3642 & LAI-NNIR \\
\hline Alpine Pine model & LAI-RVI & LAI-DVI & LAI-SAVI & 0.3578 \\
\hline$R$ & 0.6169 & 0.8104 & 0.6971 & 0.6484 \\
RMSEP & 0.5399 & 0.3778 & 0.4787 & LAI-NNIR \\
\hline Oak model & LAI-GNDVI & LAI-WDRVI & LAI-SAVI & 0.6499 \\
\hline$R$ & 0.6188 & 0.6574 & 0.6068 & 0.3264 \\
RMSEP & 0.5776 & 0.4331 & LAI-NMDI & LAI-NNIR \\
\hline Spruce-fir model & LAI-GNDVI & LAI-WDRVI & 0.7448 & 0.6820 \\
\hline$R$ & 0.6101 & 0.5613 & 0.3529 & 0.3919 \\
RMSEP & 0.4246 & 0.4479 & LAI-SAVI & LAI-NNIR \\
\hline Yunnan Pine model & LAI-RVI & LAI-NDVI & 0.5319 & 0.4020 \\
\hline$R$ & 0.6337 & 0.5295 & 0.4027 & 0.4004 \\
\hline RMSEP & 0.3612 & & & \\
\hline
\end{tabular}

types, it is found that the 3 kinds of samples from the Alpine Pine forest, Oak forest, and the Spruce-fir forest have a higher correlation than the full-sample, and the correlation $R^{2}$ of the full-sample in the analysis is less than 0.6251 . In the pine forest analysis, except for the 6 vegetation indices (NMDI, SIPI, NG, GRVI, MSAVI, and PSRI), the $R^{2}$ of the other vegetation indices is 0.6581 . This is because the vegetation cover type of the underlying surface corresponding to the whole sample is relatively complex, while the single sample vegetation type is simple, and the spectral information is more consistent. (3) The change trend of LAI with each vegetation index in the fullsample analysis is basically consistent with the trend of Yunnan pine, and the $R^{2}$ is relatively close.

\section{Inversion Accuracy Evaluation}

Because the measured LAI sample data are limited, in order to make full use of the measured data, the LAI model is validated using a verification method that is suitable for small samples and has the highest sample utilization rate. The LOOCV method is as follows (Jiang et al. 2013): Select one observation data set from $N$ observation data sets as verification data, use the remaining observation data to fit a model, and verify the accuracy of this model with the one that is excluded first, and repeat $N$ times. The predictability of the model is measured by the root-meansquare error of prediction (RMSEP) and the correlation coefficient $R$ between the observed values and the model predictions. RMSEP is often used to quantify model accuracy, and $R$ is often used to assess model accuracy. The RMSEP expression is:

$\mathrm{RMSEP}=\sqrt{\sum_{i=1}^{n}\left(\mathrm{LAI}_{\mathrm{mod}}^{i}-\mathrm{LAI}_{\mathrm{obs}}^{i}\right)^{2} / n}$

In the expression, $\mathrm{LAI}_{\mathrm{obs}}^{i}$ represents the $i$ th field observation, $\mathrm{LAI}_{\text {mod }}^{i}$ is the $i$ th prediction of model inversion, and $N$ is the total number of observations. A lower RMSEP value indicates that the regression model is more accurate. The closer the correlation coefficient $R$ is to 1 , the higher the model accuracy. We cross-validated all 34 samples, i.e., 9 Alpine Pine forest samples, 5 Oak forest samples, 7 Spruce-fir forest samples, and 13 Yunnan pine forest samples, as well as 4 kinds of vegetation indices with good fits, and then calculated the RMSEP and $R$ (Table 5).

From Tables 4 and 5, the full-sample was divided into Alpine Pine forest, Oak forest, Spruce-fir forest, and Yunnan Pine, and the coefficient of determination of the model simulation is increased by $0.1652,0.1040,0.1264$, and 0.0079 , respectively, compared with the highest $R^{2}$ of the full-sample. We can see that the best fitting models for the full-sample, Alpine Pine, Oak, Spruce-fir and Yunnan Pine are LAI-RVI, LAI-DVI, LAI-NNIR, LAI-NMDI, and LAI-RVI, respectively. However, due to the special vegetative conditions in the study area, it is difficult to realize the remote sensing differentiation of the 4 forest land types in Shangri-La City. Therefore, the full-sample model is used to invert the Shangri-La City LAI. 


\section{LAI Mapping}

Using the full-sample LAI-RVI model, $y=0.8298 x+0.1356$, the LAI was extracted and mapped on the RVI map, and the LAI inversion map of the ShangriLa City forest was obtained (Fig. 3). To further analyze the distribution characteristics of LAI, vegetation coverage (VC) was extracted from the study area in combination with land use type with a spatial resolution of $1 \mathrm{~km} \times 1$ $\mathrm{km}$. The pixel dichotomy and grading vegetation coverage [0.0-0.1 for other types, $0.1-0.45$ for low vegetation coverage (LVC), 0.45-0.65 for middle vegetation coverage (MVC), 0.65-0.75 for middle-high vegetation coverage (MHVC), and 0.75-1.0 for high vegetation coverage (HVC)], were also used, as shown in Fig. 4. The LAI value is distributed between 0.9654 and 5.5145, and the higher the VC level, the higher the LAI value. The minimum value of the next $\mathrm{VC}$ level is the maximum value of the previous VC level. With the increase in VC level, the proportion of LAI gradually increases. In the HVC region, the LAI is $47.8666 \%$ and the LAI value of this region is concentrated at 2.3151, and the corresponding land use types are forest land, shrub, and partially middle-covered and high-covered grassland (Table 6).



Fig. 3 LAI distribution map



Fig. 4 Fractional vegetation cover

Table 6 LAI statistics within each vegetation coverage

\begin{tabular}{lllll}
\hline VC level & \multicolumn{2}{l}{ LAI statistics } & & \\
\cline { 2 - 5 } & LAI $_{\min }$ & LAI $_{\max }$ & LAI $_{\text {avg }}$ & The proportion of LAI (\%) \\
\hline LVC & 0.9654 & 1.1088 & 1.0388 & 11.6327 \\
MVC & 1.1088 & 1.3816 & 1.2360 & 19.6515 \\
MHVC & 1.3816 & 1.7516 & 1.5644 & 20.8492 \\
HVC & 1.7516 & 5.5145 & 2.3151 & 47.8666 \\
\hline
\end{tabular}

\section{Conclusions and Discussion}

Using the single-band data of Landsat 8, we measured LAI to perform the quadratic polynomial regression analysis, the vegetation index was calculated for the multispectral band, and linear regression analysis was performed with the measured LAI. The model was verified by the LOOCV method, and the optimal model was selected to simulate LAI. The conclusions are as follows:

1. The multivariate model method is more effective than the univariate model method when estimating LAI. In the multivariate model for estimating LAI, the vegetation index extracted from the remote sensing image has a good correlation with measured LAI. This is similar to the results of Tang et al. (2014), who believed that the 2 variables have a better fit to the leaf 
area than the univariate ones. The best fitting indices in the full-sample, Alpine Pine forest, Oak forest, Spruce-fir forest, and Yunnan Pine forest are RVI $\left(R^{2}=0.6251\right), \quad$ DVI $\quad\left(R^{2}=0.7903\right), \quad$ WDRVI $\left(R^{2}=0.7439\right), \quad$ NMDI $\quad\left(R^{2}=0.7515\right), \quad$ and $\quad$ RVI $\left(R^{2}=0.6330\right)$, respectively. All of the samples in the study area were divided into Alpine Pine forest, Oak forest, Spruce-fir forest, and Yunnan Pine forest samples. In addition to Yunnan Pine forest, the determination coefficient of samples of other forest land is higher than full-sample in the study. Zhu et al. (2014) states that classifying a sample as a single sample has a higher coefficient of determination and simulation accuracy than in full-sample studies.

2. Using the leave-one-out method to verify the 4 kinds of indices with good fits for 5 samples, it is found that the best fitting models for the full-sample, Alpine Pine forest, Oak forest, Spruce-fir forest, and Yunnan Pine forest samples are LAI-RVI $(y=0.8298 x+0.1356$, $R=0.7501, \quad$ RMSEP $=0.3436), \quad$ LAI-DVI $(y=1.2478 x-0.0375, \quad R=0.8104, \quad$ RMSEP $=$ 0.3778), LAI-NNIR $\quad(y=5.6094 x-0.8462$, $R=0.6499, \quad$ RMSEP $=0.4263), \quad$ LAI-NMDI $(y=4.5813 x-1.6694, \quad R=0.7448, \quad$ RMSEP $=$ $0.3529), \quad$ and LAI-RVI $\quad(y=0.6866 x+0.4341$, $R=0.6337$, RMSEP $=0.3612)$, respectively.

3. In the LAI inversion, Shangri-La city LAI values are distributed from 0.9654 to 5.5145 , and the higher the VC level, the higher the LAI value. LAI is mainly distributed in the HVC area.

The estimation of the Leaf Area Index is a complicated process. The research results of estimating LAI based on the correlation between vegetation index and measured LAI are only preliminary, and many problems need to be further studied. For example, due to the limitation of data, the measured data (mainly acquired in October) have a certain degree of asynchronism, which will affect the accuracy of the inversion, so later research should strive to achieve synchronization. In addition, there are only 34 effective samples of the measured LAI, which will also have some influence on the inversion accuracy.

Acknowledgements All authors made great contributions to this study. This research was funded by the National Natural Science Foundation of China (No. 41271230) and the Reserve Personnel Training Program of Middle-aged Academic and Technology Leaders of Yunnan Province (No. 2008PY056).

\section{Compliance with Ethical Standards}

Conflict of interest All authors declare that they have no conflict of interest.
Open Access This article is distributed under the terms of the Creative Commons Attribution 4.0 International License (http://creative commons.org/licenses/by/4.0/), which permits unrestricted use, distribution, and reproduction in any medium, provided you give appropriate credit to the original author(s) and the source, provide a link to the Creative Commons license, and indicate if changes were made.

\section{References}

Chang, Y., Fan, W., \& Wen, Y. (2016). Study on seasonal dynamics of Leaf Area Index in Maoer Mountain. Forest Engineering, $32(4), 1-6$.

Chen, J. M., \& Black, T. A. (2010). Defining leaf-area index for nonflat leaves. Agricultural and Forest Meteorology, 15(4), 421-429.

Chen, J. M., Pavlic, G., Brown, L., Cihlar, J., Leblanc, S. G., White, H. P., et al. (2002). Derivation and validation of Canada-wide coarse-resolution Leaf Area Index maps using high-resolution satellite imagery and ground measurements. Remote Sensing of Environment, 80(1), 165-184.

Gitelson, A. A., Kaufman, Y. J., \& Merzlyak, M. N. (1996). Use of a green channel in remote sensing of global vegetation from EOSMODIS. Remote Sensing of Environment, 58(3), 289-298.

González-Sanpedro, M. C., Toan, T. L., Moreno, J., Kergoat, L., \& Rubio, E. (2008). Seasonal variations of Leaf Area Index of agricultural fields retrieved from Landsat data. Remote Sensing of Environment, 112(3), 810-824.

Han, T. T., Xi, X. H., Wang, C., Wang, F. J., \& Wan, Y. P. (2014). Forest Leaf Area Index inversion based on TM data in Xishuangbanna Area. Remote Sensing Information, 29(2), 28-32.

He, Y., Pan, X., Pei, Z., Ma, S., Mcnirn, H., \& Shang, J. (2013). Estimation of LAI and yield of sugarcane based on SPOT remote sensing data. Transactions of the Chinese Society for Agricultural Machinery, 44(5), 226-231.

Huang, J., Hou, Y., Su, W., Liu, J., \& Zhu, D. (2017). Mapping corn and soybean cropped area with GF-1 WFV data. Transactions of the Chinese Society of Agricultural Engineering, 33(7), 164-170.

Huete, A. R. (1988). A soil-adjusted vegetation index (SAVI). Remote Sensing of Environment, 25(3), 295-309.

Jiang, H., Song, W. J., Cai, Y., Chen, J., \& Sun, G. F. (2013). Experimental and practical teaching mode reform in experimental teaching center of public health. Laboratory Science, 16(3), 147-150.

Jordan, C. F. (1969). Derivation of leaf-area index from quality of light on the forest floor. Ecology, 50(4), 663-666.

Juutinen, S., Virtanen, T., Kondratyev, V., Laurila, T., Linkosalmi, M., Mikola, J., et al. (2017). Spatial variation and seasonal dynamics of leaf-area index in the arctic tundra-implications for linking ground observations and satellite images. Environmental Research Letters, 12(9), 095002.

Li, Y. F., Mao, D. H., Wang, Z. M., Lu, C. Y., Zhang, L., \& Lou, Y. J. (2014). Remote sensing retrieval and spatial pattern analysis of Leaf Area Index of Phragmites australis in Shuangtai Estuary National Nature Reserve. Wetland Science, 12(2), 163-169.

Li, X. H., Song, X. N., \& Leng, P. (2011). A quantitative method for grassland LAI inversion based on CHRIS/PROBA data. Remote Sensing for Land and Resources, 19(3), 61-66.

Li, M. M., Wu, B. F., \& Yan, C. Z. (2004). Estimation of vegetation fraction in the upper basin of Miyun Reservoir by remote sensing. Resources Science, 26(4), 153-159. 
Luo, S., Cheng, F., Wang, F., Xi, X., \& Wang, C. (2012). Leaf Area Index inversion based on TM in Linzhi, Tibet. Remote Sensing Technology and Application, 27(5), 740-745.

Merzlyak, M. N., Gitelson, A. A., Chivkunova, O. B., \& Rakitin, V. Y. (2010). Non-destructive optical detection of pigment changes during leaf senescence and fruit ripening. Physiologia Plantarum, 106(1), 135-141.

Penuelas, J., Filella, I., \& Gamon, J. A. (2010). Assessment of photosynthetic radiation-use efficiency with spectral reflectance. New Phytologist, 131(3), 291-296.

Qi, J., Chehbouni, A., Huete, A. R., Kerr, Y. H., \& Sorooshian, S. (1994). A modified soil adjusted vegetation index. Remote Sensing of Environment, 48(2), 119-126.

Ren, Z., Chen, H., Wang, L., Ying, L. I., \& Qi, L. I. (2015). Research on inversion model of wheat LAI using cross-validation. Remote Sensing for Land and Resources, 27(4), 34-40.

Roujean, J. L., \& Breon, F. M. (1995). Estimating PAR absorbed by vegetation from bidirectional reflectance measurements. Remote Sensing of Environment, 51(3), 375-384.

Sripada, R. P., White, J. G., Crozier, C. R., Heiniger, R. W., Weisz, R., Burleson, J., et al. (2005). Aerial color infrared photography for determining in-season nitrogen requirements for corn. Agronomy Journal, 97(5), 1511-1514.

Su, W., Hou, N., Li, Q., \& Zhang, M. Z. (2018). Retrieving Leaf Area Index of corn canopy based on sentinel-2 remote sensing image. Transactions of The Chinese Society of Agricultural Machinery, 49(1), 151-156.

Tang, S. L., Jia, X., Guo, J. B., Chen, Z. H., Zha, T. S., Qin, S. G., et al. (2014). Measuring and modeling Leaf Area Index for Artemisia ordosica. Chinese Journal of Ecology, 32(10), 547-554.

Tucker, C. J. (1979). Red and photographic infrared linear combinations for monitoring vegetation. Remote Sensing of Environment, 8(2), 127-150.

Wang, Q., Adiku, S., Tenhunen, J., \& Granier, A. (2005). On the relationship of NDVI with Leaf Area Index in a deciduous forest site. Remote Sensing of Environment, 94(2), 244-255.
Wang, L. H., Du, J., Huang, J. L., Yang, R. X., \& Huang, W. (2016). Retrieving Leaf Area Index of maize based on GF-1 multispectral remote sensing data. Journal of Central China Normal University, 50(1), 120-127.

Wang, C., Du, H. Q., Zhou, G. M., Xu, X. J., Sun, S. B., \& Gao, G. L. (2015). Retrieval of crown closure of moso bamboo forest using unmanned aerial vehicle (UAV) remotely sensed imagery based on geometric-optical model. Chinese Journal of Applied Ecology, 26(5), 1501.

Wang, L., \& Qu, J. J. (2007). NMDI: a Normalized Multi-band Drought Index for monitoring soil and vegetation moisture with satellite remote sensing. Geophysical Research Letters, 34(20), $117-131$.

Wang, J. X., Xiong, Q. C., Lin, Q. N., \& Huang, H. G. (2018). Feasibility of using mobile phone to estimate forest Leaf Area Index: a case study in Yunnan Pine. Remote Sensing Letters, 9(2), 180-188.

Xu, Q. Z., Zhang, W. C., Liu, S. C., Zhao, D. Z., \& Jiang, J. J. (2003). Retrieval of Leaf Area Index for the Heihe River Watershed by using remote sensing data. Arid Zone Research, 20(4), 281-285.

Yao, X., Yu, K. Y., Yang, Y. J., Zeng, Q., Chen, Z. H., \& Liu, J. (2017). Estimation of forest Leaf Area Index based on random forest model and remote sensing data. Transactions of the Chinese Society for Agricultural Machinery, 48(5), 159-166.

Zhang, C. L., Yang, G. J., Li, H. L., Tang, F. Q., Liu, C., \& Zhang, L. Y. (2018). Remote sensing inversion of Leaf Area Index of winter wheat based on random forest algorithm. Scientia Agricultura Sinica, 51(5), 855-867.

Zhu, X. C., Yuan, G. F., Yi, X. B., \& Du, T. (2014). Leaf Area Index inversion of riparian forest in the lower basin of Tarim River based on Landsat 8 OLI images. Arid Land Geography, 37(6), $1248-1256$.

Publisher's Note Springer Nature remains neutral with regard to jurisdictional claims in published maps and institutional affiliations. 